\title{
Bu open Descriptive analysis of the respiratory health status of persons exposed to Libby amphibole asbestos
}

\author{
Charlene A Winters, ${ }^{1}$ Wade G Hill, ${ }^{1}$ Kimberly Rowse, ${ }^{2}$ Brad Black, ${ }^{2}$ \\ Sandra W Kuntz, ${ }^{1}$ Clarann Weinert ${ }^{1}$
}

To cite: Winters CA, Hill WG, Rowse $\mathrm{K}$, et al. Descriptive analysis of the respiratory health status of persons exposed to Libby amphibole asbestos. BMJ Open 2012;2: e001552. doi:10.1136/ bmjopen-2012-001552

- Prepublication history and additional material for this paper are available online. To view these files please visit the journal online (http://dx.doi.org/10.1136/ bmjopen-2012-001552).

Received 23 May 2012 Accepted 18 October 2012

This final article is available for use under the terms of the Creative Commons Attribution Non-Commercial 2.0 Licence; see http://bmjopen.bmj.com

${ }^{1}$ Montana State University, College of Nursing, Bozeman, Montana, USA

${ }^{2}$ Center for Asbestos Related Disease, Libby, Montana, USA

Correspondence to Dr Charlene A Winters; winters@montana.edu

\section{ABSTRACT}

Objective: Describe respiratory health and quality of life in persons exposed to Libby amphibole asbestos (LAA) contaminated vermiculite.

Design: Cross-sectional descriptive.

Setting: Asbestos-related disease clinic in Libby, Montana USA.

Participants: 329 individuals exposed to LAA; mostly men, married, between 50 and 69 years; two-thirds lived in the surrounding county; one-third lived elsewhere in the state and USA.

Primary outcome measures: Chest radiograph (CXR), pulmonary function data and the St George Respiratory Questionnaire (SGRQ).

Results: Exposure categories included vermiculite workers $=7.6 \%$; family/household contact of vermiculite worker $=32 \%$; and environmental exposure only $=60 \%$. Of the participants, $55 \%$ had only pleural abnormalities; $5.4 \%$ had only interstitial abnormalities; nearly $21 \%$ had both abnormalities and $18 \%$ had no lung abnormality on chest $x$-ray. Mean forced vital capacity (FVC) $95.3 \%(\mathrm{SD}=18.7)$; forced expiratory volume ( $\mathrm{FEV}_{1}$ ) mean $87 \%(\mathrm{SD}=20.2)$; ratio of $\mathrm{FEV} 1_{1} /$ FVC 95.5\% (SD=12.0); and diffusing capacity (DLCO) of $83 \%(S D=21.7)$ of the percent predicted. The mean total SGRQ (38.5; SD=22.1) indicated a lower quality of life than healthy persons and persons with other chronic conditions. SGRQ subscale means were Symptoms 52.1 ( $S D=24.9)$, activity $49.4(S D=26.9)$ and impacts $27.5(S D=21.9)$. Participants with normal CXR differed significantly from those with both interstitial and pleural abnormalities on total, activity and impacts scores. For activity alone, subjects with normal CXR differed significantly from those with pleural disease; no differences were found for those with interstitial disease. Significant findings were found for smoking history across all pulmonary measures, and for exposure status, radiographic findings, age and gender for select pulmonary parameters. Subjects with any smoking history had significantly worse average total and subscale scores on the SGRQ.

Conclusions: Of 329 persons exposed to LAA, the majority (182) had pleural abnormalities identified on CXR. SGRQ scores for persons with abnormalities (pleural, interstitial or both) (269) differed significantly from those with a normal CXR.

\section{ARTICLE SUMMARY}

Article focus

- Overall health and respiratory quality of life in persons exposed to Libby amphibole asbestos (LAA) using clinical data and the St George Respiratory Questionnaire (SGRQ).

\section{Key messages}

- In 329 participants where $60 \%$ had only environmental exposure to LAA, $55 \%$ had pleural abnormalities alone, $5.4 \%$ had only interstitial abnormalities $18 \%$ had no abnormalities noted on chest $x$-ray, and overall quality of life was poorer than in healthy persons and persons with chronic obstructive pulmonary disease.

- For participants with evidence of both interstitial and pleural abnormalities, FVC, $\mathrm{FEV}_{1}$ and $\mathrm{DL}_{\mathrm{CO}}$, differed significantly from those participants with normal chest radiograph (CXR) diagnostics.

- Poorer SGRQ scores and findings of pleural and interstitial abnormalities and diminished pulmonary function in persons with low lifetime cumulative amphibole asbestos exposure is important given the widespread distribution and use of LAA-contaminated material in private and commercial applications.

Strengths and limitations of this study

- Only study to describe the health status and respiratory quality of life in persons exposed to LAA.

- Only study to use the SGRQ with persons exposed to LAA.

- Cross-sectional design.

- Real-time quality-of-life data and the most recent pulmonary data.

- Significant lack of sensitivity of standard CXR in the detection and characterisation of significant asbestos-related pleural and parenchymal fibrosis.

- Participants were at varying stages of health and illness and given that ARD is a progressive disease that evolves over 10-plus years, the results of the study provide a snapshot in time of the pulmonary and quality-of-life status of participants. 


\section{INTRODUCTION}

Asbestosis is one of several chronic illnesses commonly linked to exposure to microscopic asbestos fibres. Pleural fibrosis, lung cancer, mesothelioma, a rare cancer of the chest lining and other cancers are also caused by exposure to asbestos. ${ }^{1}$ The physical properties of asbestos are instrumental in causing asbestos-related diseases (ARDs). Amphibole fibres are characteristically straight, rigid and needle-like. These fine $(<5 \mu \mathrm{m}$ in diameter), straight and short fibres (5-20 $\mu \mathrm{m}$ long) are less likely to be cleared from the airways than are thick, longer fibres and can cause intense inflammation and fibrotic changes in the lung interstitium. ${ }^{2}$ Once exposed, it can take 10 or more years before respiratory compromise is noted. ${ }^{3}$ The pleura are particularly sensitive to the effects of the fibres, causing pleural plaques to develop after low, intermittent exposure. Pleural effusions are often the earliest manifestation of ARD. ${ }^{5}$ Shortness of breath (dyspnoea) often accompanied by rales (crackles) or cough is common. ${ }^{67}$ Deficits occur in pulmonary function variables such as forced expiratory volume in $1 \mathrm{~s}\left(\mathrm{FEV}_{1}\right)$, forced vital capacity (FVC), total lung capacity (TLC) and diffusing capacity (DLCO).$^{8-12}$

National mortality surveillance of occupation-related respiratory diseases designated asbestosis as the leading pneumoconiosis recorded on death certificates from 1982 to $2000 .^{13}$ While death rates decreased for other previously dominant occupational lung diseases, American deaths attributed to asbestosis steadily increased from 77 deaths in 1968 to 1493 in $2000 .^{14}$ Deaths due to asbestosis continued to rise in older individuals aged 75-84 years until 2005 and then levelled off while deaths in younger individuals aged 45-74 years peaked earlier, ${ }^{15}$ a trend consistent with a legacy of past exposures and a downward trend in asbestos usage.

A significant source of exposure to amphibole asbestos in the USA came from contaminated vermiculite ore mined and processed in rural Libby, Montana from the early 1920s until 1990 when the mine closed. The raw ore, which is estimated to have contained as much as $26 \%$ amphibole asbestos ${ }^{16}$ was distributed to over 250 regional processing plants then shipped to nearly every state in the USA. Vermiculite is widely used in consumer products, such as attic insulation, lawn and garden products and fireproofing material. ${ }^{5}$ In the years of operation, millions of tons of vermiculite were produced at the mine, providing nearly $80 \%$ of the world's supply.

Air sampling in Libby in the 1980s identified asbestos fibres in excess of occupational limits of $0.1 \mathrm{fibre} / \mathrm{cm}^{3}$ over $8 \mathrm{~h}$ set by the Occupational Safety and Health Administration. ${ }^{17}$ As early as 1986, a cohort study (1963-1983) detected increased death rates among Libby vermiculite mine workers. ${ }^{19}$ In addition to the occupational exposure associated with vermiculite mining and handling, household members of vermiculite workers and residents of Libby without connections to the mining operations were exposed when the product was distributed throughout town and used for gardening, insulation, driveways and a school baseball field. ${ }^{20}$

Increasing national attention focused on Libby, Montana in November 1999 when increasing numbers of local residents were diagnosed with ARD. From 1979 to 1998 asbestosis mortality in Libby was 40-80 times higher than expected for Montana and the USA, respectively. $^{21}$ In 2000 and 2001, medical screenings of more than 6668 current and former Libby residents were conducted. Pleural abnormalities were observed on chest x-ray in $18 \%$ of participants and interstitial abnormalities in $<1 \%$ of participants who were screened. ${ }^{20} 22$ Fifty-one per cent of the former vermiculite workers who were x-rayed and $26 \%$ of household contacts of workers had pleural abnormalities. By comparison, the rate of pleural abnormalities in non-asbestos exposed groups in the USA ranges from $0.2 \%$ to $2.3 \% .^{16}$

In February of 2002, after extensive review, the US Environmental Protection Agency (EPA) placed Libby on the National Priorities List and the area became a Superfund asbestos cleanup and removal site. In June of $2008,{ }^{23}$ updated asbestosis mortality statistics were released for 1995-2004. Lincoln County Montana where Libby is located had the highest age-adjusted asbestosis death rate per million population in the USA for residents age 15 and older. In 2009, 7 years after the Superfund designation, the EPA declared a public health emergency in Libby, the first such determination under the Comprehensive Environmental Response, Compensation, and Liability Act (Libby Public Health Emergency, http://www.epa.gov/region8/superfund/ libby/phe.html). The declaration constitutes formal recognition of the serious health impacts from asbestos contamination in the Libby community.

The association between specific exposure pathways and radiographic abnormalities has been reported ${ }^{19} 20$ 24-26 Scant information has been published on overall responses to exposure, for example, access to healthcare ${ }^{27}$ and psychosocial ramifications ${ }^{28}$ in this population. The quality of life of persons exposed to Libby amphibole asbestos (LAA) has not been described.

\section{PURPOSE}

The purpose of this paper is to describe the respiratory health status (aim 1) and respiratory health-related quality of life (aim 2) of a cohort of persons exposed to LAA.

\section{METHODS}

\section{Study design}

A descriptive cross-sectional design was used for the study. Participants were patients of the Center for Asbestos Related Disease (CARD) in Libby, Montana. CARD provides long-term health screening, monitoring, ARD diagnosis, specialised asbestos healthcare and counselling to people affected by exposure to LAA. Clinical records and the results of chest radiographs 
(CXR) and pulmonary function tests (PFT) were examined to determine the severity of respiratory illness. Results from the St George Respiratory Questionnaire (SGRQ) were used to determine respiratory health-related quality of life and demographic information was used to describe the cohort.

The study was conducted under the auspices of the Institutional Review Board at Montana State University. Written informed consent was obtained from all participants prior to data collection. Each participant was assigned a unique study code number and deidentified data were used in the analysis.

\section{Participants}

Because this was a cross-sectional descriptive study, a large sample was sought. Primary data were collected on 485 CARD patients but the final sample yielded a total of 329 participants based on incomplete secondary clinical data from chart review. Eligible participants were patients of the CARD clinic with a history of exposure to LAA, 21 years of age or older, with the ability to speak, read and write English. To publicise the study, descriptive posters and brochures that described the study's intent to examine overall health status of persons exposed to LAA were available in the CARD clinic waiting room. On an individual basis, each client presenting to the CARD for their annual examination were approached and invited to participate. Those who met the inclusion criteria and consented completed either an electronic or paper version of the SGRQ and demographic questionnaire during their clinic visit. CARD clients, who lived outside the Libby area in Montana or elsewhere in the USA, also were invited to participate in the study by including a letter describing the study, consent form and a paper copy of the study questionnaire with normal annual correspondence. Although it is not known if enrolled patients of the CARD clinic differ from those not enrolled in this study, staff report very few clients that were approached declined to participate. CXR and PFT results along with other clinical data were extracted from each participant's medical record by a CARD staff member and provided to the research team. Data were collected from February to December 2007.

\section{Measures}

The measures used to describe the respiratory health status included results from the annual or most recent CXR and PFT, two tests routinely used to monitor respiratory status in CARD patients. Chest films consisted of anterior/posterior and lateral views interpreted by a single community-based radiologist. Chest x-rays are an insensitive method of diagnosing asbestos-related disease in this population. The International Labour Organization (ILO) classification was not utilised; rather, readers experienced in asbestos-related disease, specifically pleural disease were utilised. Data collected for the study included the radiologist's reading of the participants' latest CXR, recorded as no abnormality, pleural abnormality, interstitial abnormality, or both pleural and interstitial abnormalities.

PFT is a generic term used to indicate a battery of tests performed using standardised equipment to measure lung function. ${ }^{29}$ PFT testing at the CARD clinic was performed by trained respiratory therapy staff using Medgraphics Platinum Elite Series Plethysmograph, (model Elite DL) and following standard testing procedures. ${ }^{30}$ Results obtained were based on standardised reference values adjusted for height, age and gender reported by Knudson $e t a \hat{l}^{31}$ The most recent results of the FVC, FEV in $1 \mathrm{~s}\left(\mathrm{FEV}_{1}\right)$, forced $\mathrm{FEV}_{1} / \mathrm{FEV}_{1}$ ratio and diffusing capacity of carbon dioxide $\left(\mathrm{DL}_{\mathrm{CO}}\right)$ were evaluated for this study.

Participants' perceptions of respiratory health-related quality of life (HRQOL) were measured using the SGRQ, an instrument routinely used by the CARD clinic to monitor clients' perceptions of their respiratory health status. The SGRQ is a 76-item standardised questionnaire for measuring impaired health and perceived HRQOL in airway disease. Impairment is measured in terms of 'symptoms' (frequency and severity of respiratory symptoms), 'activity' (activities that cause or are limited by breathlessness), 'impacts' (social functioning and psychological disturbances related to respiratory problems) and a total score (sums and weights of above components). ${ }^{32}$ Potential SGRQ scores range from 0 (no impairment) to 100 (the worst impairment) for each subscale, with higher scores indicating greater distress and worse HRQOL. Previous studies showed good reliability, cross-sectional and longitudinal validity of the SGRQ. ${ }^{33-36}$ Cronbach's $\alpha$-coefficients for this study were 0.887 (total), 0.713 (symptoms), 0.913 (activity) and 0.908 (impacts). The total score and scores for the subscales were collected for this study as a measure of respiratory HRQOL.

\section{Data management}

Survey data collected electronically were transmitted directly and electronically to a protected database at the research office at Montana State University through a secure Internet connection. The paper/pencil questionnaire data and the deidentified medical record data were entered into an electronic file by the CARD research team members and sent directly and electronically to the research office. All data were exported into SPSS (V.16, 2001) on an ongoing basis. Summary results from the SGRQ for individual participants were reported to the CARD clinic on a weekly basis using the unique study number as they had a potential impact on the individual's plan of care. Ultimately, all questionnaire data became a part of the client's health record at the CARD clinic. To address the research questions posed in this study a one-way analysis of variance (ANOVA) was used to examine group differences in pulmonary function and respiratory related quality of life based on gender, age, smoking status, exposure source and radiographic 
findings. Significant omnibus tests of differences were followed by appropriate post hoc analysis to identify specific group differences.

\section{RESULTS}

Of the 329 study participants, two-thirds lived in Lincoln County (local patients) and one-third lived elsewhere in Montana and throughout the USA (distant patients). More men than woman participated, most were married, had a history of smoking and $70 \%$ were between 50 and 69 years of age (see table 1 ).

Aim 1 of this study explored respiratory morbidity among this cohort by measured pulmonary function. Means and SDs for measures of pulmonary function are included in table 2A,B (analysed as percent predicted). For the total sample of 329 persons exposed to LAA, the mean $\quad \mathrm{FVC}$ was $95.3 \% \quad(\mathrm{SD}=18.7), \quad \mathrm{FEV}_{1} \quad 87.0 \%$ $(\mathrm{SD}=20.2)$, ratio of $\mathrm{FEV}_{1} / \mathrm{FVC} 95.5 \% \quad(\mathrm{SD}=12.0)$ and $\mathrm{DL}_{\mathrm{CO}} 83.0 \%(\mathrm{SD}=21.7)$.

A one-way ANOVA was used to examine differences in pulmonary function including $\mathrm{FVC}, \mathrm{FEV}_{1}, \mathrm{FEV}_{1} / \mathrm{FVC}$ ratio and $\mathrm{DL}_{\mathrm{CO}}$ according to gender, age, smoking history, exposure status and findings from CXR. The ANOVA summary table $2 \mathrm{~A}, \mathrm{~B}$ indicate that omnibus differences were found based on smoking history and findings for FVC; age, smoking history and findings for $\mathrm{FEV}_{1}$; smoking history alone for $\mathrm{FEV}_{1} / \mathrm{FVC}$; and gender,

\begin{tabular}{|c|c|c|}
\hline & $\begin{array}{l}\text { Subjects } \\
(n=329)\end{array}$ & $\begin{array}{l}\text { Sample } \\
\text { (\%) }\end{array}$ \\
\hline \multicolumn{3}{|l|}{ Age } \\
\hline $20-49$ & 39 & 11.9 \\
\hline $50-59$ & 112 & 34.0 \\
\hline $60-69$ & 120 & 36.5 \\
\hline $70+$ & 58 & 17.6 \\
\hline \multicolumn{3}{|l|}{ Marital status } \\
\hline Married & 239 & 72.6 \\
\hline Single & 27 & 8.2 \\
\hline Widow(er) & 30 & 9.1 \\
\hline Divorced & 29 & 8.8 \\
\hline Separated & 4 & 1.2 \\
\hline \multicolumn{3}{|l|}{ Insurance status (not exclusive) } \\
\hline HNA & 204 & 62.0 \\
\hline LAMP screening & 124 & 37.7 \\
\hline LAMP supplemental & 179 & 54.4 \\
\hline Other & 167 & 50.8 \\
\hline \multicolumn{3}{|l|}{ Gender } \\
\hline Men & 187 & 56.8 \\
\hline Women & 142 & 43.2 \\
\hline \multicolumn{3}{|l|}{ Location } \\
\hline Local & 219 & 66.6 \\
\hline Distant & 110 & 33.4 \\
\hline \multicolumn{3}{|l|}{ Exposure route } \\
\hline Worker & 25 & 7.6 \\
\hline Household member/contact & 106 & 30.2 \\
\hline Other & 198 & 62.2 \\
\hline
\end{tabular}

age, smoking and findings for $\mathrm{DL}_{\mathrm{CO}}$. ANOVA findings examining differences in PFT's based on radiographic findings were confirmed with a follow-up Kruskal-Wallis test due to violations in distributional assumptions. Post hoc analyses using the Tukey HSD test indicated that for FVC, $\mathrm{FEV}_{1}$ and $\mathrm{DL}_{\mathrm{CO}}$, participants with a normal CXR had better pulmonary function from those with evidence of both interstitial and pleural abnormalities. For FVC alone, those with pleural or interstitial abnormalities scored similarly although only the difference between normal CXR and CXR showing pleural abnormalities was detected by the ANOVA, likely as a result of increasing variability when sample size dropped to only 18 persons in the interstitial only group. A similar finding can be seen for $\mathrm{FEV}_{1}$ as results indicated that participants scored similarly from both the pleural and interstitial group although only the difference with the interstitial group was detected. Post hoc analysis for $\mathrm{DL}_{\mathrm{CO}}$ showed that the youngest age group (20-49) scored significantly better than the other three groups, and as expected, the oldest age group of persons (over 70 years) fared the worst.

Aim 2 of this study was to explore respiratory related quality of life among this cohort using results from the SGRQ. Means and SDs for the entire SGRQ scale and each of the three subscales (symptoms, activity and impacts) are included in table 3A,B. The overall score of the total scale among this cohort was $38.5(\mathrm{SD}=22.1)$ and means for the subscales were $52.1(\mathrm{SD}=24.9), 49.4$ $(\mathrm{SD}=26.9)$ and $27.5(\mathrm{SD}=21.9)$ for symptoms, activity and impacts, respectively.

Subgroup analysis was conducted to evaluate potential differences within this sample identical to the PFT analysis. A one-way ANOVA was used to examine differences in respiratory health-related quality of life (SGRQ total, symptoms, activity and impacts) according to gender, age, smoking history, exposure status and radiographic findings. The ANOVA summary table 3A,B indicated that omnibus differences were found based on smoking history and radiographic findings for SGRQ total; smoking history for symptoms; smoking history and radiographic findings for activity; and smoking history, and radiographic findings for impacts.

ANOVA findings examining differences in PFT's based on radiographic findings were confirmed with a follow-up Kruskal-Wallis test due to violations in distributional assumptions. Post hoc analyses using the Tukey HSD test indicated that participants scored significantly higher for activity limitations if they had any evidence of abnormality on CXR and were more significantly affected if they had either pleural abnormalities or both pleural and interstitial abnormalities. In addition, for the total score on the SGRQ, those subjects with either pleural abnormalities or evidence of both pleural and interstitial abnormalities appeared to score worse. Those subjects with any smoking history had significantly worse average scores overall and on the three subscales of the SGRQ. 
Table 2 Pulmonary function of Libby ARD cohort

\begin{tabular}{|c|c|c|c|c|c|c|c|c|c|}
\hline Panel A & $\mathbf{N}$ & $\begin{array}{l}\text { FVC* } \\
\text { Mean (SD) }\end{array}$ & $\mathbf{F}$ & $\begin{array}{l}p \\
\text { Value }\end{array}$ & $\begin{array}{l}\text { Pair } \\
\text { differences } †\end{array}$ & $\begin{array}{l}\text { FEV1 }_{1} \\
\text { mean } \\
\text { (SD) }\end{array}$ & $\mathbf{F}$ & $\begin{array}{l}p \\
\text { Value } \\
\end{array}$ & $\begin{array}{l}\text { Pair } \\
\text { differences }\end{array}$ \\
\hline Total & 329 & $95.3(18.7)$ & - & - & - & $87.0(20.2)$ & - & - & - \\
\hline \multicolumn{10}{|l|}{ Gender } \\
\hline Male & 187 & $95.7(19.3)$ & \multirow[t]{2}{*}{0.19} & \multirow[t]{2}{*}{0.66} & \multirow[t]{2}{*}{ NA } & 87.3 (19.7) & \multirow[t]{2}{*}{0.10} & \multirow[t]{2}{*}{0.76} & \multirow[t]{2}{*}{ NA } \\
\hline Female & 142 & 94.7 (18.0) & & & & $86.6(20.8)$ & & & \\
\hline \multicolumn{10}{|l|}{ Age } \\
\hline $20-49(0)$ & 39 & $100.1(14.8)$ & \multirow[t]{4}{*}{1.43} & \multirow[t]{4}{*}{0.23} & \multirow[t]{4}{*}{ NA } & 96.5 (14.3) & \multirow[t]{4}{*}{3.79} & \multirow[t]{4}{*}{0.01} & 0 vs 2 \\
\hline 50-59 (1) & 112 & $95.0(21.6)$ & & & & 87.9 (23.0) & & & 0 vs 3 \\
\hline $60-69(2)$ & 120 & $94.2(18.7)$ & & & & $85.1(19.4)$ & & & \\
\hline $70+(3)$ & 58 & $94.0(14.4)$ & & & & $83.3(17.8)$ & & & \\
\hline \multicolumn{10}{|l|}{ Smoker } \\
\hline Yes (ever) & 215 & $93.8(20.1)$ & \multirow[t]{2}{*}{3.63} & \multirow[t]{2}{*}{0.05} & \multirow[t]{2}{*}{ NA } & $84.1(20.6)$ & \multirow[t]{2}{*}{13.30} & \multirow[t]{2}{*}{0.00} & \multirow[t]{2}{*}{ NA } \\
\hline No & 114 & $98.0(15.5)$ & & & & $92.5(18.1)$ & & & \\
\hline \multicolumn{10}{|l|}{ Exposure } \\
\hline Worker & 25 & 95.2 (17.9) & \multirow[t]{3}{*}{0.84} & 0.43 & NA & 89.0 (18.9) & 0.39 & 0.68 & NA \\
\hline Family/contact & 106 & $93.4(17.1)$ & & & & 85.7 (19.8) & & & \\
\hline Other & 198 & $96.3(19.7)$ & & & & $87.5(20.6)$ & & & \\
\hline Radiographic findings & & & & & & & & & \\
\hline Normal (0) & 60 & $103.8(15.0)$ & 7.40 & 0.00 & 0 vs 1 & $92.8(21.8)$ & 4.33 & 0.00 & 0 vs 3 \\
\hline Pleural abnormalities (1) & 182 & 94.9 (20.2) & & & 0 vs 3 & 87.7 (20.0) & & & 1 vs 3 \\
\hline Interstitial abnormalities (2) & 18 & $95.6(12.0)$ & & & & $86.4(16.5)$ & & & \\
\hline Both (3) & 69 & $88.8(16.3)$ & & & & $80.4(18.6)$ & & & \\
\hline Panel B & $\mathbf{n}$ & $\begin{array}{l}\text { FEV1 }_{1} / \\
\text { FVC }_{1} \\
\text { Mean (SD) }\end{array}$ & $\mathbf{F}$ & $\begin{array}{l}p \\
\text { Value }\end{array}$ & $\begin{array}{l}\text { Pair } \\
\text { differencest }\end{array}$ & $\begin{array}{l}\text { DLCO* } \\
\text { Mean } \\
\text { (SD) }\end{array}$ & $\mathbf{F}$ & $\begin{array}{l}p \\
\text { Value }\end{array}$ & $\begin{array}{l}\text { Pair } \\
\text { differences }\end{array}$ \\
\hline Total & 329 & $95.5(12.0)$ & - & - & - & $83.0(21.7)$ & - & - & - \\
\hline Gender & & & & & & & & & \\
\hline Male & 187 & $96.1(11.9)$ & 1.02 & 0.31 & NA & $86.3(21.7)$ & 10.13 & 0.00 & NA \\
\hline Female & 142 & 94.8 (12.2) & & & & $78.7(21.0)$ & & & \\
\hline Age & & & & & & & & & \\
\hline $20-49(0)$ & 39 & $98.4(8.5)$ & 1.22 & 0.30 & NA & $91.5(18.6)$ & 9.31 & 0.00 & 0 vs 2 \\
\hline $50-59$ (1) & 112 & 95.5 (13.3) & & & & $87.6(22.2)$ & & & 0 vs 3 \\
\hline $60-69(2)$ & 120 & 95.6 (10.9) & & & & 81.1 (19.9) & & & 1 vs 3 \\
\hline $70+(3)$ & 58 & $93.6(13.4)$ & & & & $72.3(21.8)$ & & & 2 vs 3 \\
\hline Smoker & & & & & & & & & \\
\hline Yes (ever) & 215 & $93.3(13.2)$ & 23.4 & 0.00 & NA & $78.5(21.9)$ & 29.00 & 0.00 & NA \\
\hline No & 114 & $99.8(7.6)$ & & & & $91.5(18.5)$ & & & \\
\hline Exposure & & & & & & & & & \\
\hline Worker & 25 & $99.0(9.3)$ & 1.15 & 0.32 & NA & $89.8(19.2)$ & 2.10 & 0.13 & NA \\
\hline Family/contact & 106 & $95.5(11.6)$ & & & & $80.4(19.4)$ & & & \\
\hline Other & 198 & $95.1(12.5)$ & & & & $83.6(23.0)$ & & & \\
\hline Radiographic & & & & & & & & & \\
\hline Findings & 60 & $94.8(13.6)$ & 0.16 & 0.92 & NA & $90.2(19.5)$ & 11.10 & 0.00 & 0 vs 2 \\
\hline Normal (0) & 182 & $95.85(10.8)$ & & & & $85.7(20.1)$ & & & 0 vs 3 \\
\hline Pleural abnormalities (1) & 18 & 94.7 (12.6) & & & & $68.1(24.5)$ & & & 1 vs 2 \\
\hline $\begin{array}{l}\text { Interstitial abnormalities (2) } \\
\text { Both (3) }\end{array}$ & 69 & $95.6(13.5)$ & & & & $73.7(22.4)$ & & & 1 vs 3 \\
\hline
\end{tabular}

Table 4 compares the Libby SGRQ mean scores with scores obtained from a representative population sample. Ferrer $e t a t^{45}$ examined SGRQ results from a subset of the 'IBERPOC (epidemiological study of chronic obstructive disease in Spain)' ( $p$ 406) to establish population norms for a respiratory-specific health-related quality-of-life tool. Table 5 compares the Libby cohort SGRQ results with the general population norms based on gender, age, and the category 'never smoked'. 
Table 3 Respiratory quality of life

\begin{tabular}{|c|c|c|c|c|c|c|c|c|c|}
\hline Panel A & $\mathbf{n}$ & $\begin{array}{l}\text { SGRQ total } \\
\text { Mean (SD) }\end{array}$ & $\mathbf{F}$ & $\begin{array}{l}\mathbf{p} \\
\text { Value }\end{array}$ & $\begin{array}{l}\text { Pair } \\
\text { differences* }\end{array}$ & $\begin{array}{l}\text { Symptoms } \\
\text { Mean (SD) }\end{array}$ & $\mathbf{F}$ & $\begin{array}{l}p \\
\text { Value }\end{array}$ & $\begin{array}{l}\text { Pair } \\
\text { differences }\end{array}$ \\
\hline Total & 329 & $38.5(22.1)$ & - & - & - & 52.1 (24.9) & - & - & - \\
\hline \multicolumn{10}{|l|}{ Gender } \\
\hline Male & 187 & $35.3(22.1)$ & \multirow[t]{2}{*}{0.03} & \multirow[t]{2}{*}{0.86} & \multirow[t]{2}{*}{ NA } & $52.1(24.5)$ & \multirow[t]{2}{*}{0.00} & \multirow[t]{2}{*}{0.99} & \multirow[t]{2}{*}{ NA } \\
\hline Female & 142 & $38.8(22.3)$ & & & & $52.0(25.4)$ & & & \\
\hline \multicolumn{10}{|l|}{ Age } \\
\hline 20-49 & 39 & 32.3 (20.3) & \multirow[t]{4}{*}{1.43} & \multirow[t]{4}{*}{0.23} & \multirow[t]{4}{*}{ NA } & $52.0(21.4)$ & \multirow[t]{4}{*}{0.76} & \multirow[t]{4}{*}{0.51} & \multirow[t]{4}{*}{ NA } \\
\hline $50-59$ & 112 & 40.1 (23.3) & & & & $54.1(25.4)$ & & & \\
\hline $60-69$ & 120 & $40.0(21.8)$ & & & & $52.1(25.4)$ & & & \\
\hline $70+$ & 58 & 37.1 (21.3) & & & & $48.0(25.1)$ & & & \\
\hline \multicolumn{10}{|l|}{ Smoker } \\
\hline Yes (ever) & 215 & $40.1(22.1)$ & \multirow[t]{2}{*}{7.10} & \multirow[t]{2}{*}{0.00} & \multirow[t]{2}{*}{ NA } & $54.0(25.4)$ & \multirow[t]{2}{*}{3.80} & \multirow[t]{2}{*}{0.05} & \multirow[t]{2}{*}{ NA } \\
\hline No & 114 & $34.0(21.5)$ & & & & $48.4(23.4)$ & & & \\
\hline \multicolumn{10}{|l|}{ Exposure } \\
\hline Worker & 25 & $35.2(25.0)$ & 0.63 & 0.53 & NA & $49.1(31.0)$ & 0.20 & 0.82 & NA \\
\hline Family/Contact & 106 & $40.2(22.0)$ & & & & $52.5(23.4)$ & & & \\
\hline Other & 198 & 38.1 (21.9) & & & & $52.2(25.0)$ & & & \\
\hline Radiographic Findings & & & & & & & & & \\
\hline Normal (0) & 60 & $29.8(20.8)$ & 4.76 & 0.00 & 0 vs 1 & $47.1(24.2)$ & 1.54 & 0.20 & NA \\
\hline Pleural abnormalities (1) & 182 & $39.1(22.5)$ & & & 0 vs 3 & $51.8(25.1)$ & & & \\
\hline Interstitial abnormalities (2) & 18 & $41.3(21.5)$ & & & & $54.5(27.0)$ & & & \\
\hline Both(3) & 69 & $43.8(20.4)$ & & & & $56.3(23.8)$ & & & \\
\hline Panel B & $\mathbf{n}$ & $\begin{array}{l}\text { Activity } \\
\text { Mean (SD) }\end{array}$ & $\mathbf{F}$ & $\begin{array}{l}\mathbf{p} \\
\text { Value }\end{array}$ & $\begin{array}{l}\text { Pair } \\
\text { differences* }\end{array}$ & $\begin{array}{l}\text { Impacts } \\
\text { Mean (SD) }\end{array}$ & $\mathbf{F}$ & $\begin{array}{l}p \\
\text { Value }\end{array}$ & $\begin{array}{l}\text { Pair } \\
\text { differences }\end{array}$ \\
\hline Total & 329 & $49.4(26.9)$ & - & - & - & $27.5(21.9)$ & - & - & - \\
\hline Gender & & & & & & & & & \\
\hline Male & 187 & $47.8(27.1)$ & 1.40 & 0.23 & NA & $28.2(21.6)$ & 0.42 & 0.51 & NA \\
\hline Female & 142 & $51.4(26.7)$ & & & & $26.6(22.3)$ & & & \\
\hline Age & & & & & & & & & \\
\hline 20-49 & 39 & $39.2(28.5)$ & 2.30 & 0.07 & NA & $21.8(18.5)$ & 1.98 & 0.13 & NA \\
\hline $50-59$ & 112 & $49.4(28.5)$ & & & & $30.1(22.5)$ & & & \\
\hline $60-69$ & 120 & $51.3(25.1)$ & & & & $28.6(22.4)$ & & & \\
\hline $70+$ & 58 & $52.2(25.4)$ & & & & $24.3(21.1)$ & & & \\
\hline Smoker & & & & & & & & & \\
\hline Yes (ever) & 215 & $52.1(26.3)$ & 6.70 & 0.01 & NA & $30.0(22.1)$ & 6.38 & 0.01 & NA \\
\hline No & 114 & $44.2(27.4)$ & & & & $23.4(21.0)$ & & & \\
\hline Exposure & & & & & & & & & \\
\hline Worker & 25 & $45.0(30.0)$ & 1.20 & 0.30 & NA & $24.8(24.1)$ & 0.34 & 0.71 & NA \\
\hline Family/Contact & 106 & $52.5(25.8)$ & & & & $28.7(22.8)$ & & & \\
\hline Other & 198 & $48.3(27.1)$ & & & & $27.3(21.2)$ & & & \\
\hline Radiographic Findings & & & & & & & & & \\
\hline Normal(0) & 60 & $36.5(26.8)$ & 7.41 & 0.00 & 0 vs 1 & $20.1(19.2)$ & & & 0 vs 1 \\
\hline Pleural abnormalities (1) & 182 & $49.9(27.4)$ & & & 0 vs 2 & $28.4(21.2)$ & 3.22 & 0.02 & 0 vs 3 \\
\hline Interstitial abnormalities (2) & 18 & $54.6(22.3)$ & & & 0 vs 3 & $28.5(23.4)$ & & & \\
\hline Both(3) & 69 & $57.7(23.0)$ & & & & $31.4(21.8)$ & & & \\
\hline
\end{tabular}

\section{DISCUSSION}

In 2002, Libby Montana was placed on the EPA priorities list and work began to clean up the amphibole asbestos contaminating the community. Seven years later, the EPA formally recognised the serious health implications of asbestos contamination in Libby by declaring a public health emergency. The study reported here was conducted between the time the clean-up began and the health emergency was declared.
In this cross-sectional, descriptive study, $18 \%$ of the study cohort $(n=60)$ had a normal CXR, a finding slightly higher than the $10-15 \%$ previously reported for persons with ARD. ${ }^{3}$ A small number of participants exhibited interstitial abnormalities $(5.4 \%)$ alone on CXR while the majority had pleural abnormalities $(55 \%)$ or both pleural and interstitial disease $(20.9 \%)$. These findings support studies showing that exposure to amphibole asbestos can lead to increased risk of structural changes 
Table 4 Libby comparison with general population norms on the St George Respiratory Questionnaire

\begin{tabular}{llcll}
\hline Study Group & Symptoms & Activity & Impacts & Total \\
\hline Libby $(n=329)$ & $52.1(24.9)$ & $49.4(26.9)$ & $27.5(21.9)$ & $38.5(22.1)$ \\
General population $(n=862)$ & $9.67(13.24)$ & $13.40(17.63)$ & $4.73(9.92)$ & $8.41(11.33)$ \\
\hline Data are presented as mean and (SD) for the Libby cohort and the general population norms (Ferrer et al). ${ }^{45}$ &
\end{tabular}

in the pleura alone. ${ }^{4} 20$ Nearly one-third of participants with pulmonary abnormalities were family or household contacts of vermiculite workers and $60 \%$ reported only environmental exposure to LAA. This important finding of environmental exposure alone, for example, nonvermiculite worker or household member of vermiculite worker provides support for studies which demonstrated that pleural and interstitial changes can occur at low lifetime cumulative amphibole fibre exposure levels. ${ }^{20}$ 37-40 With the widespread distribution of the Libby vermiculite, pulmonary changes due to low-level exposure have significant public health implications.

The pulmonary function indicators showed low normal mean values for the total cohort for $\mathrm{FEV1}_{1}$ (87\%) and $\mathrm{DL}_{\mathrm{CO}}(83.0 \%)$ (normal $>80 \%$ of predicted value). Significant differences were found in $\mathrm{FEV}_{1}$ based on age, smoking history and radiographic findings, while smoking history alone was related to significant changes in $\mathrm{FEV}_{1} / \mathrm{FVC}$ ratio. Analysis of correlates with these lung function parameters is complicated by the clinical observation by the study authors that adult-onset obstructive airway disease (no history of smoking, asthma) frequently occurs in the Libby cohort in association with the development of asbestos-related pleural +/- parenchymal disease. A diagnosis of adult onset asthma is commonly present in individuals presenting to CARD for screening who have evidence of ARD. Although the American Thoracic Society Statement ${ }^{41}$ addresses the relationship of chronic airway obstruction to asbestos exposure, the frequency and severity have been observed to be greater in the Libby cohort. Thus, contributions to significant airway obstruction decreased $\mathrm{FEV}_{1}$ and/or low $\mathrm{FEV}_{1} /$ FVC could arise from asbestos ${ }^{42}$ as well as smoking. Differences in $\mathrm{DL}_{\mathrm{CO}}$ were associated with gender, age, smoking history and radiographic findings. Lower $\mathrm{FEV}_{1}$ and $\mathrm{DL}_{\mathrm{CO}}$ are consistent with restrictive lung disease (eg, respiratory fibrosis) and conditions caused by fibrogenic dusts (eg, asbestos) and smoking. ${ }^{29}$ Ross $^{3}$ reported that
$\mathrm{DL}_{\mathrm{CO}}$ can be reduced in approximately $80-90 \%$ of persons with asbestosis.

Mean FVC value for the cohort was 95.3\%. Differences in FVC were found based on exposure status, smoking and radiographic findings although significant differences between groups were not identified. Pleural thickening has been shown to impair lung function measured by pulmonary function testing and diffuse pleural scarring is associated with reduced FVC and $\mathrm{DL}_{\mathrm{CO}}{ }^{43}{ }^{44}$ This finding is clinically significant as it strongly suggests that pleural abnormalities on radiograph correlate with relative restrictive changes across this population and could be associated with dyspnoea on exertion resulting from the more diffuse pleural abnormalities.

The Libby cohort demonstrated a total SGRQ score of 38.5 on a scale of $0-100$ with a higher score indicating worse HRQOL. Subjects with any smoking history had significantly worse average total scores and on the three subscales of the SGRQ. For activity alone, subjects with normal radiographic findings differed significantly from those with pleural evidence of disease but no differences were found for those with interstitial evidence. When compared with persons with chronic obstructive pulmonary disease (COPD) and interstitial lung disease, the Libby cohort's HRQOL total scores were worse. However, when comparing the Libby cohort to the general population (tables 4 and 5), the findings indicated significantly worse quality of life. ${ }^{45}$ Small changes in scores are meaningful; a difference of four points is considered clinically significant. ${ }^{46}$ Interestingly, as with the Libby cohort, the general population of women was higher than men on the activity scale but lower than men on impacts. As expected, the general population symptoms, activity and impact scores increased with age while the Libby cohort symptoms and impact scores actually decreased possibly related to accommodation of the chronic condition. Libby individuals noting 'no or never smoked' compared with the general population

Table 5 St George Respiratory Questionnaire Libby and general population comparison based on characteristics

\begin{tabular}{|c|c|c|c|c|c|c|c|c|}
\hline & \multicolumn{2}{|c|}{ Symptoms } & \multicolumn{2}{|c|}{ Activity } & \multicolumn{2}{|l|}{ Impact } & \multicolumn{2}{|l|}{ Total } \\
\hline & Libby & General & Libby & General & Libby & General & Libby & General \\
\hline \multicolumn{9}{|l|}{ Gender } \\
\hline Male & 52.1 & 11.62 & 47.8 & 12.17 & 28.2 & 5.23 & 35.3 & 8.60 \\
\hline Female & 52.0 & 7.82 & 51.4 & 14.58 & 26.6 & 4.26 & 38.8 & 8.23 \\
\hline \multicolumn{9}{|l|}{ Age } \\
\hline 50-59 & 54.1 & 8.74 & 49.4 & 13.48 & 30.1 & 4.55 & 40.1 & 8.19 \\
\hline $60-69$ & 52.1 & 12.54 & 51.3 & 17.95 & 28.6 & 7.23 & 40.0 & 11.61 \\
\hline Never smoked & 48.4 & 7.49 & 44.2 & 13.63 & 23.4 & 4.16 & 34.0 & \\
\hline
\end{tabular}


indicate a significantly lower quality of life related to asbestos-related disease despite smoking status.

\section{LIMITATIONS}

While this study provides important information about respiratory morbidity and quality of life among a unique population, results should be interpreted with caution due to the limitations of our cross-sectional design. It is not known for example how well our sample represents the population of those experiencing ARD as a result of exposures to LAA, or exactly how physical and quality-of-life changes occur during disease progression. As we have observed clinically, morbidity is often worse when a relative change occurs within the individual associated with an evolving disease process and single measurements despite apparent severity serve a less useful role. Future research will enable individual trends to be evaluated for respiratory morbidity and associated quality of life and provide a more complete prospective dataset that will allow greater statistical flexibility including multivariate analysis.

It is also important to note that the SGRQ data were collected from participants upon enrolment in the study while the pulmonary data (CXR and PFT) and exposure history represent the most recent data documented in the participant's health record and may not represent current pulmonary and exposure status. Also, although CXRs were read by the same radiologist, well recognised is the significant lack of sensitivity of standard CXR in the detection and characterisation of significant asbestos-related pleural and parenchymal fibrosis. This is especially true for non-calcified pleural thickening, where the anterior and posterior chest is poorly visualised. The Libby population exposed to the amphibole mixture predominately presents with non-calcified diffuse pleural thickening, ${ }^{16} 3847$ making CXR even less sensitive. In addition, subjects needed only to be patients of CARD with documented exposure to LAA to participate in the study resulting in a sample of participants at varying stages of health and illness. Given that ARD is a progressive disease that evolves over 10-plus years, the results of the study provide a snapshot in time of the pulmonary and HRQOL status of participants.

\section{CONCLUSIONS}

In this study of 329 persons exposed to LAA, pleural abnormalities alone were noted in 55\% of participants; nearly $21 \%$ had both pleural and interstitial abnormalities, while only $18 \%$ of study participants had no documented lung abnormality on chest x-ray. Nearly 35\% had never smoked. The mean FVC for the cohort was 95.3\% (SD=18.7); $\mathrm{FEV}_{1} 87 \%$ ( $\left.\mathrm{SD}=20.2\right)$; ratio of $\mathrm{FEV}_{1}$ / FVC $95.5 \%(\mathrm{SD}=12)$ and $\mathrm{DL}_{\mathrm{CO}}$ was $83 \%(\mathrm{SD}=21.7)$ of the per cent predicted. Significant findings were found based on smoking history across all pulmonary measures, and for exposure status, radiographic findings, age and gender for select pulmonary parameters. The mean total SGRQ for the cohort was $38.5 \quad(\mathrm{SD}=22.1)$ indicating a significantly lower HRQOL than is found in healthy persons and appreciably worse than some persons with COPD or interstitial lung disease. Means for the SGRQ subscales were $52.1 \quad(\mathrm{SD}=24.9), 49.4$ $(\mathrm{SD}=26.9)$ and $27.5(\mathrm{SD}=21.9)$ for symptoms, activity and impacts, respectively. Subjects with normal CXR differed significantly from those with evidence of both interstitial and pleural abnormalities on total, activity and impacts scores. For activity alone, subjects with normal radiographic findings differed significantly (higher function) from those with pleural evidence of disease but no differences were found for those with interstitial evidence. Subjects with any smoking history had significantly worse average total scores and on the three subscales of the SGRQ.

The SGRQ findings in this cohort of subjects are noteworthy for clinicians. Furthermore, the finding of pleural and interstitial abnormalities and diminished pulmonary function in persons with low lifetime cumulative amphibole fibre exposure, for example, non-vermiculite worker or household member of a vermiculite worker, is important given the widespread distribution and use of vermiculite ore in private and commercial applications. Holistic healthcare that addresses the psychosocial and physiological aspects of health is an important consideration in persons exposed to or living with the health effects of LAA. ${ }^{28}$ Routine screening of individuals at risk for ARD and those with pleural or interstitial abnormalities using tools like the SGRQ is essential to the provision of early psychosocial intervention and support for respiratory-related QOL issues. More research is needed to understand the psychosocial and physical costs of exposure to LAA.

Acknowledgements The authors thank the participants for their engagement in the study, Ms Amber Spring for her grants management, CARD staff for their assistance with recruiting, and acknowledge the funding from the U.S. Health Resources and Services Administration Office of Rural Health Policy (R04RH07544).

Contributors CAW was the principle investigator; WGH, SWK and CW were coinvestigators on the study. KR was engaged in data collection; $\mathrm{TH}$ provided case management for participants with needs resulting from participation and BB served as medical advisor for the study. Each member participated in the development and implementation of the study, analysis of the data, and dissemination of results. CAW, WGH, KR and BB drafted the manuscript and all co-authors critically revised the paper.

Funding Funded by US Health Resources and Services Administration Office of Rural Health Policy.

Competing interests None.

Ethics approval Montana State University.

Provenance and peer review Not commissioned; externally peer reviewed.

Data sharing statement No additional data are available.

\section{REFERENCES}

1. American Lung Association. Occupational lung disease fact sheet, 2005.

2. Khan AN. Asbestos-related disease imaging. Medscape Reference 2011. http://emedicine.medscape.com/article/353015-overview (accessed 12 Jun 2010). 
3. Ross RM. The clinical diagnosis of asbestosis in this century requires more than a chest radiograph. Chest 2003;124:1120-8.

4. Whitehouse AC. Asbestos-related pleural disease due to tremolite associated with progressive loss of lung function: Serial observations in 123 miners, family members, and residents of Libby, Montana. Am J Ind Med 2004:46:219-25.

5. Environmental Protection Agency. ABCs of Asbestos, 2005.

6. Churg A. Nonneoplastic asbestos-induced disease. Mt Sinai J Med 1986;53:409-15.

7. Enarson DA, Embree V, MacLean L, et al. Respiratory health in chrysotile asbestos miners in British Columbia: a longitudinal study. Br J Ind Med 1988;45:459-63.

8. Guidotti TL, Miller A, Christiani DC, et al. Nonmalignant asbestos-related disease: diagnosis and early management. Clin Pulm Med 2007;14:82-92.

9. Glencross PM, Weinberg JM, Ibrahim JG, et al. Loss of lung function among sheet metal workers: ten-year study. Am J Ind Med 1997;32:460-6.

10. Kilburn $\mathrm{KH}$, Warshaw $\mathrm{RH}$. Airways obstruction from asbestos exposure. Effects of asbestosis and smoking. Chest 1994;106: 1061-70.

11. Shepherd JR, Hillerdal G, McLarty J. Progression of pleural and parenchymal disease on chest radiographs of workers exposed to amosite asbestos. Occup Environ Med 1997;54:410-15.

12. Finkelstein M. Pulmonary function in asbestos cement workers: a dose-response study. Br J Ind Med 1986;43:406-13.

13. Centers for Disease Control and Prevention. Changing patterns of pneumoconiosis mortality-United States, 1968-2000. Mortality Morbidity Weekly Report. Centers for Disease Control and Prevention 2004:627-32.

14. Middendorf $\mathrm{P}$, Zumwalde R, Castellan R. Asbestos and Other Mineral Fibers:A Roadmap for Scientific Research: Department of Health and Human Services, Centers for Disease Control and Prevention, National Institute for Occupational Safety and Health, 2007.

15. Attfield MD, Bang KM, Petsonk EL, et al. Trends in pneumoconiosis mortality and morbidity for the United States, 1968-2005, and relationship with indicators of extent of exposure. J Phys: Conference Series 2009;150:1-10.

16. Agency for Toxic Substances and Disease Registry. ATSDR Public Health Assessment, 2003

17. Atkinson GR, Rose $\mathrm{D}$, Thomas $\mathrm{K}$, et al. Collection, analysis, and characterization of vermiculite samples for fiber content and asbestos contamination: US Environmental Protection Agency Contract 68-01-5915, 1982.

18. Dixon GH, Doria J, Freed JR, Wood P, May I, Chambers T, et al. Exposure Assessment for Asbestos-Contaminated Vermiculite. EPA560/5-85-013. Washington, DC, USA: Environmental Protection Agency, Office of Pesticides and Toxic Substances, 1985.

19. McDonald JC, McDonald AD, Armstrong B, et al. Cohort study of mortality of vermiculite miners exposed to tremolite. $\mathrm{Br} \mathrm{J}$ Ind Med 1986;43:436-44.

20. Peipins LA, Lewin M, Campolucci S, et al. Radiographic abnormalities and exposure to asbestos-contaminated vermiculite in the community of Libby, Montana, USA. Environ Health Perspect 2003;111:1753-9.

21. Agency for Toxic Substances and Disease Registry. ATSDR health consultation for the Libby community: Mortality in Libby, Montana, 1979-1998. Atlanta, Georgia: Agency for Toxic Substances and Disease Registry, 2002.

22. Agency for Toxic Substances and Disease Registry. Health Consultation: Mortality from asbestosis in Libby, Montana. Atlanta, Georgia: Agency for Toxic Substances and Disease Registry, 2000.

23. National Institute for Occupational Safety and Health. Work-Related Lung Disease (WoRLD) Surveillance System. 2008;1: Asbestosis Mortality.

24. Lockey JE, Brooks SM, Jarabek AM, et al. Pulmonary changes after exposure to vermiculite contaminated with fibrous tremolite. Am Rev Respir Dis 1984;129:952-8.
25. McDonald JC, McDonald AD, Sebastien P, et al. Health of vermiculite miners exposed to trace amounts of fibrous tremolite. Br J Ind Med 1988;45:630-4.

26. McDonald JC, Sebastien P, Armstrong B. Radiological survey of past and present vermiculite miners exposed to tremolite. $\mathrm{Br} J$ Ind Med 1986;43:445-9.

27. Winters CA, Hill W, Kuntz SW, et al. Determining satisfaction with access and financial aspects of care for persons exposed to Libby amphibole asbestos: rural and national environmental policy implications. J Environ Public Health 2011;2011:789514.

28. Weinert C, Hill WG, Winters CA, et al. Psychosocial health status of persons seeking treatment for exposure to libby amphibole asbestos. ISRN Nurs 2011;2011:735936.

29. Gildea TR, McCarthy K. Pulmonary function testing, 2008

30. National Institute for Occupational Safety and Health (NIOSH). $\mathrm{NIOSH}$ spirometry training guide, 2003.

31. Knudson RJ, Slatin RC, Lebowitz MD, et al. The maximal expiratory flow-volume curve. Normal standards, variability, and effects of age. Am Rev Respir Dis 1976;113:587-600.

32. Jones PW, Quirk FH, Baveystock CM. The St George's Respiratory Questionnaire. Respir Med 1991;85(Suppl B):25-31; discussion 33-7.

33. Harper R, Brazier JE, Waterhouse JC, et al. Comparison of outcome measures for patients with chronic obstructive pulmonary disease (COPD) in an outpatient setting. Thorax 1997;52:879-87.

34. Jones PW, Quirk FH, Baveystock CM, et al. A self-complete measure of health status for chronic airflow limitation. The St. George's Respiratory Questionnaire. Am Rev Respir Dis 1992;145:1321-7.

35. Puhan MA, Guyatt GH, Goldstein R, et al. Relative responsiveness of the Chronic Respiratory Questionnaire, St. Georges Respiratory Questionnaire and four other health-related quality of life instruments for patients with chronic lung disease. Respir Med 2007;101:308-16.

36. Singh SJ, Sodergren SC, Hyland ME, et al. A comparison of three disease-specific and two generic health-status measures to evaluate the outcome of pulmonary rehabilitation in COPD. Respir Med 2001:95:71-7.

37. Bandli BR, Gunter ME. A review of scientific literature examining the mining history, geology, mineralogy, and amphibole asbestos health effects of the Rainy Creek igneous complex, Libby, Montana, USA. Inhal Toxicol 2006;18:949-62.

38. Rohs AM, Lockey JE, Dunning KK, et al. Low-level fiber-induced radiographic changes caused by Libby vermiculite: a 25 -year follow-up study. Am J Respir Crit Care Med 2008;177:630-7.

39. Alexander $\mathrm{BH}$, Raleigh KK, Johnson J, et al. Radiographic Evidence of nonoccupational asbestos exposure from processing libby vermiculite in Minneapolis, Minnesota. Environ Health Perspect 2012;12044-49.

40. Larson TC, Antao VC, Bove FJ, et al. Association between cumulative fiber exposure and respiratory outcomes among Libby vermiculite workers. J Occup Environ Med 2012;54:56-63.

41. American Thoracic Society. Diagnosis and initial management of nonmalignant diseases related to asbestos. Am J Respir Crit Care Med 2004;170:691-715.

42. Wilken D, Garrido MV, Manuwald U, et al. Lung function in asbestos-exposed workers, a systematic review and meta-analysis. J Occup Med Toxicol 2011;6:21.

43. Schwartz D. New developments in asbestos-induced pleural disease. Chest 1991:99:191-8.

44. Schwartz DA, Davis CS, Merchant JA, et al. Longitudinal changes in lung function among asbestos-exposed workers. Am J Respir Crit Care Med 1994;150:1243-9.

45. Ferrer M, Villasante $\mathrm{C}$, Alonso $\mathrm{J}$, et al. Interpretation of quality of life scores from the St George's Respiratory Questionnaire. Eur Respir $J$ 2002;19:405-13.

46. Jones PW. Interpreting thresholds for a clinically significant change in health status in asthma and COPD. Eur Respir $J$ 2002;19:398-404.

47. Miles S, Sandrini A, Johnson A, et al. Clinical consequences of asbestos-related diffuse pleural thickening: a review. J Occup Med Toxicol 2008;3:20. 